\title{
Single Stage Catalytic Hydrodeoxygenation of Pretreated Bio-oil
}

\author{
Yan Luo, ${ }^{\mathrm{a}, \mathrm{b} *}$ Xuan Zhou, ${ }^{\mathrm{a}, \mathrm{b}}$ Hui Pu, ${ }^{\mathrm{c}}$ Hongling Pan, ${ }^{\mathrm{a}, \mathrm{b}}$ Xiao Feng, ${ }^{\mathrm{b}}$ Wenhai Ding, ${ }^{\mathrm{b}}$ \\ Chenfan Ding, ${ }^{\mathrm{b}}$ and Yiheng Dang ${ }^{\mathrm{b}}$
}

\begin{abstract}
Raw bio-oil was pretreated and tested for hydrodeoxygenation (HDO) using three types of the commercial catalysts (HT-36, HT2300, and HT951T) to improve physio-chemical properties and enhance hydrocarbon yields. The three catalysts prompted different levels of hydrodeoxygenation, and the organic phase products (OLPs) yields were 25.30, 27.83, and $13.05 \mathrm{wt} \%$, respectively. Moreover, OLPs had lower water content, total acid numbers (TAN), and $\mathrm{O}$ content as well as higher heating value $(\mathrm{HHV}), \mathrm{C}$, and $\mathrm{H}$ contents. For the three catalysts, HT-36 had the best HDO effects, resulting in $34.8 \%$ hydrocarbon production with improved $\mathrm{HHV}$, water content value and TAN as well as element contents. The different level of HDO depended on the catalyst components, structure, and morphology. This research is beneficial for the selection and preparation of effective catalysts for bio-oil upgrading.
\end{abstract}

Keywords: Bio-oil; Hydrodeoxygenation; Catalyst; GC-MS

Contact information: a. Civil Aircraft Fire Science And Safety Engineering Key Laboratory of Sichuan Province, Civil Aviation Flight University of China, Guanghan 618307, China; b: College of Civil Aviation Safety Engineering, Civil Aviation Flight University of China, Guanghan 618307, China; c: Nanchong Natural Gas Company Limited of PetroChina, Nanchong 637000, China;

*Corresponding author: luohaiyanabc@163.com

\section{INTRODUCTION}

Declining fossil fuel resources, environmental regulations regarding greenhouse gas emissions from fossil fuel combustion, and a desire to discontinue dependence on oil have led to the development of alternatives (Wei et al. 2018; Chen et al. 2018; Fang et al. 2018; Zhang et al. 2019; Fang 2019, 2020; Hu et al. 2020; Zou et al. 2020). Lignocellulosic biomass, due to its carbon value, abundance, and renewability, is a potential resource for biofuel production via thermochemical conversion technologies such as fast pyrolysis (Anis and Zainal 2011; Zhang et al. 2017).

Fast pyrolysis is the thermal decomposition of biomass in the absence of air to produce a liquid (bio-oil) precursor to fuels and chemicals. Fast pyrolysis applies a high heat transfer rate to the biomass particles, a very short vapor residence time in the heating zone, and the rapid condensation of the pyrolysis vapors to produce bio-oil (Luo et al. 2016a, b). Bio-oil is a dark, viscous liquid with a higher heating value (HHV) of 17 to 18 $\mathrm{MJ} / \mathrm{Kg}$. The presence of water and numerous chemical compounds in a variety of reactive functional groups such as carbonyl compounds (aldehydes and ketones), acids, esters, phenols, etc., makes bio-oil highly oxygenated, acidic $(\mathrm{pH} 2.5)$, and subject to phase separation and polymerization over time or with heating (Bridgwater and Meier 1999; Elliott et al. 2012).

A number of methods have been applied to upgrade bio-oil to high-quality fuels, including catalytic hydrotreating to hydrocarbons (Lee and Ollis 1984; Ardiyanti et al. 
2012; Elliott and Hart 2012), catalytic reforming (Cortright et al. 2002; Trane et al. 2012), catalytic pyrolysis (Shi et al. 2011), esterification (Cui and Wang 2010), and supercritical treatment (Cui et al. 2010). Catalytic hydrotreating includes catalytic partial deoxygenation and full deoxygenation. When pressurized hydrogen is used for the deoxygenation step, partial deoxygenation is termed hydrotreating, and full deoxygenation is termed hydrocracking. The catalysts play an important role in partial and full deoxygenation processes. Mortensen et al. (2011) summarized the common catalysts used in hydrodeoxygenation and hydrocracking.

A two-stage method was developed by adding a full deoxygenation hydrocracking step to the mild partial deoxygenating (Elliott and Baker 1989; Baker and Elliott 1993). This partial step by hydrotreating and removal of gasoline-weight cyclic components allowed full deoxygenation to be applied at a higher temperature without bio-oil polymerization.

Elliott (2007) showed that full deoxygenation reduces oxygenate content by a large amount in the range of 94.5 to $98.4 \%$. These experiments support the efficacy of the $2^{\text {nd }}$ stage treatment of bio-oil by partial followed by full deoxygenation in a two-step process in a reactor with two temperature zones. Elliott and Hart (2009) tested lower hydrotreating and higher hydrocracking temperatures for several different bio-oil types in a continuousflow fixed-bed reactor system. The authors first applied $\mathrm{Pd} / \mathrm{C}$ catalysts to partially deoxygenate the bio-oil. Elliott and Hart (2012) also applied a bench-scale continuous-flow fixed-bed reactor system for upgrading two different bio-oils produced by fast pyrolysis. The top bed utilized sulfided $\mathrm{Ru} / \mathrm{C}$ catalysts at a low temperature of about $170{ }^{\circ} \mathrm{C}$, and the bottom bed utilized sulfided $\mathrm{CoMo}$ or $\mathrm{NiMo} / \mathrm{Al}_{2} \mathrm{O}_{3}$ catalysts at a higher temperature of about $400{ }^{\circ} \mathrm{C}$.

Marker and Petri (2009) applied partial and full deoxygenation to produce diesel and naphtha boiling point range fuels from pyrolysis lignin fractioned from biomass. The organic phase was subjected to a $2^{\text {nd }}$-stage hydrocracking treatment in the temperature range of 340 to $435^{\circ} \mathrm{C}$ at a hydrogen pressure of 500 to $1800 \mathrm{psi}$ to produce gasoline and diesel products. McCall and Brandvold (2009) applied a partial deoxygenation followed by full deoxygenation in a two-heating-zone continuous reactor. The oxygen removal rates of the partial and full deoxygenation processes were 89.1 and $96 \%$, respectively, depending on the catalyst type and reaction conditions. Joshi and Lawal (2012) studied the pyrolysis oil on hydrotreating with sulfided $\mathrm{NiMo} / \mathrm{Al}_{2} \mathrm{O}_{3}$ catalysts in a small diameter microreactor for the $1^{\text {st }}$-stage hydrodeoxygenation (HDO) to eliminate a percentage of oxygen.

The objective of this research is to upgrade the pretreated bio-oil in a single stage HDO in the presence of three commercial catalysts. This research will benefit the selection and synthesis of more effective catalysts for bio-oil upgrading.

\section{EXPERIMENTAL}

\section{Materials}

Bio-oil for this study was produced by pyrolysis of pine wood biomass chipped to 1 to $3 \mathrm{~mm}$ in diameter at a temperature of $450{ }^{\circ} \mathrm{C}$ in the presence of nitrogen. The pyrolyzed gas was condensed and collected as raw bio-oil (RBO). More information about bio-oil production could be found in the previous research work (Luo et al. 2016a,b, 2017). The commercial catalysts HT-2003, HT-951T, and HT-36 were purchased from Liaoning 
Haitai Sci-Tech Development Co. Ltd. (Liaoning, China). The details of the three catalysts are listed in Table 1.

Table 1. Detailed Information of the Three Type Catalysts

\begin{tabular}{|c|c|c|c|}
\hline Properties/Catalysts & HT-36 & HT-951T & HT-2003 \\
\hline Appearance & Clover shape & Clover shape & Blue grey Stripe \\
\hline Size $(\mathrm{mm})$ & $4.2-8$ & $3-10$ & $1.2-1.8$ \\
\hline Bulk density $\left(\mathrm{kg} / \mathrm{m}^{3}\right)$ & - & $0.5-0.6$ & - \\
\hline $\mathrm{CoO}(\mathrm{wt} \%)$ & - & $1.8 \pm 0.3$ & $3.0-4.0$ \\
\hline $\mathrm{MoO}_{3}(\mathrm{wt} \%)$ & $22-25$ & $9.5 \pm 0.5$ & $18-22$ \\
\hline Edgewise compressive strength (N/cm) & $\geq 16$ & - & 140 \\
\hline Bulk density (kg/L) & $0.88-0.94$ & - & $0.8-0.90$ \\
\hline $\mathrm{TiO}_{2}(\mathrm{wt} \%)$ & - & - & $11-13$ \\
\hline $\mathrm{SiO}_{2}(\mathrm{wt} \%)$ & $3-5$ & $3-4$ & $2-3$ \\
\hline Surface area $\left(\mathrm{m}^{2} / \mathrm{g}\right)$ & $\geq 160$ & 300 & - \\
\hline $\mathrm{Aperture}(\mathrm{mL} / \mathrm{g})$ & $0.32-0.38$ & 0.4 & - \\
\hline $\mathrm{P}_{2} \mathrm{O}_{5}(\mathrm{wt} \%)$ & 3 & 3 & - \\
\hline $\mathrm{NiO}(\mathrm{wt} \%)$ & $3.6-4.4$ & - & - \\
\hline
\end{tabular}

\section{Single Stage HDO of PTBO in the Parr Reactor}

Raw bio-oil was pretreated using the previously described method, and the product was named as pretreated bio-oil (PTBO) (Luo et al. 2016a,b, 2017). The HDO of PTBO with pressurized hydrogen was conducted in a stainless high pressure batch autoclave. The PTBO and catalysts were weighed and then placed in a batch autoclave. The autoclave was closed tightly, and pressurized gas was injected into the reaction system to drive out air and test the sealing of the system. After the system seal was tested, pressurized gas was flushed into the reactor, all the valves was closed, and the water cooling valve was opened. The pressure and the temperature were recorded during the reaction process every $15 \mathrm{~min}$ before it reached experimental temperature. When the reaction was complete, the reactor was cooled, and the pressure was released to atmospheric pressure. Both liquid and gas samples were collected. The experimental conditions are listed in Table 2.

Table 2. Experimental Condition Details

\begin{tabular}{|c|c|c|c|c|c|}
\hline Catalysts & Weight (g) & PTBO & Weight (g) & $\begin{array}{c}\text { Initial } \mathrm{H}_{2} \\
\text { Pressure }(\mathrm{psi})\end{array}$ & Reaction Time (h) \\
\hline HT-36 & 10 & $5 \%$ & 100 & 1000 & 3 \\
\hline HT-2300 & 11 & $5 \%$ & 100 & 1000 & 3 \\
\hline HT-951T & 10 & $5 \%$ & 100 & 1000 & 3 \\
\hline
\end{tabular}

\section{Physical and Chemical Properties Analysis}

After the reaction was complete, the liquid products were collected, weighed, and centrifuged for $4 \mathrm{~h}$ at $4000 \mathrm{rpm}$ to separate organic and water phases. The liquid yields were calculated using Eq. 1,

$$
\text { Yields }(w t \%)=\left(M_{1} \times 100\right) / M \text { РТВO }
$$

where $M_{1}$ is the mass of liquid organic products $(\mathrm{g})$; PTBO is short for pretreated bio-oil; and $М$ Ртво is the mass of PTBO (g).

The basic properties of organic liquid phase (OLPs), including water content, higher heating value (HHV) and total acid value (TAN), were determined by the 
appropriate ASTM standard method (ASTM International, West Conshohocken, USA.). Water content was determined by Karl-Fisher titration according to ASTM D5291-01 method (Thermo Fisher Scientific Inc., Waltham, USA). HHV was determined by Ika5000 bomb calorimeter (Parr Instrument Co., Moline, USA) according to ASTM D2401919 method. TAN was determined by titrating $1 \mathrm{~g}$ of bio-oil sample (dissolved in 35/65 vol/vol isopropanol and water mixture) with $0.05 \mathrm{~N} \mathrm{NaOH}$ to $\mathrm{pH} 8.5$ as the end point by ASTM D664-07 method. Elemental analysis was performed using a Varian 3500 FTIR analyzer according to ASTM D3291 method with a standard of acetanilide $(\mathrm{C}=71.09 \mathrm{wt} \%$, $\mathrm{H}=6.71 \mathrm{wt} \%, \mathrm{~N}=10.36 \mathrm{wt} \%$, and $\mathrm{H}=11.84 \mathrm{wt} \%$ ). (Exeter Analytical, MA, USA).

\section{Gas Chromatography-Mass Spectrometry (GC-MS) Analysis of OLPs}

The volatile and semi-volatile components of each specimen were analyzed by a Hewlett Packard 5971 series mass spectrometer (GC-MS; Hewlett-Packard Company, CA, USA), as previously described (Luo et al. 2016c,d).

\section{Gas Chromatography (GC) Analysis of Exit Gas}

Exit gases were collected into 1-L Tedlar gas bags and analyzed within two days after production by a gas chromatograph (SRI 8610C, SRI, CA, USA) equipped with thermal conductivity (TCD) and flame ionization (FID) detectors, as in previous research (Luo et al. 2016a b).

\section{RESULTS AND DISCUSSION}

\section{Basic Physical Information of the OLPs}

Oxidation of bio-oil improves OLP yield and reduces char production (Steele and Tanneru 2013; Tanneru and Steele 2014). In this research, BO was oxidized to PTBO, followed by single-stage HDO to produce OLPs. The physical and chemical properties of BO and PTBO have been discussed in previous research (Luo et al. 2016a,b). The basic information of the products using three different catalysts was listed in Table 3. For the OLPs yield, the HT 2300 catalyst had the highest yield, followed by HT-36 catalyst, while the HT-951T had the lowest OLPs yield. The yields were 25.3, 27.8, and $13.0 \mathrm{wt} \%$, respectively. For HHV, water content, value and TAN number, HT-36 catalyst showed the best performance of $40.4 \mathrm{MJ} / \mathrm{Kg}, 1.37 \mathrm{vol} . \%$, and $3.85 \mathrm{mg} \mathrm{KOH} / \mathrm{g}$, respectively, followed by HT-951T with $39.8 \mathrm{MJ} / \mathrm{Kg}, 3.28 \mathrm{vol} . \%$, and $1.10 \mathrm{mg} \mathrm{KOH} / \mathrm{g}$. For elemental analysis, all the OLP had higher $\mathrm{C}$ and $\mathrm{H}$ content and less $\mathrm{O}$ content, which indicated that all the three catalysts were effective for HDO. Moreover, OLP obtained from HT-36 catalyst contained the highest $\mathrm{C}$ content of $83.3 \mathrm{wt} \%$ and $\mathrm{H}$ content of $10.5 \mathrm{wt} \%$, but the lowest $\mathrm{O}$ content of $6.17 \mathrm{wt} \%$.

Compared with PTBO, all the properties of the OLPs obtained from the single stage HDO process were improved, resulting in lower water content, TAN number, and $\mathrm{O}$ content as well as higher $\mathrm{HHV}$ value, $\mathrm{C}$, and $\mathrm{H}$ contents. Based on the above information, the HT-36 catalyst had the best HDO performance, which was due to conversion of the oxygenates in the PTBO. The difference catalytic performance was due to the composition, structure, and morphology of the catalysts. The HT-36 catalysts with Ni, Mo, P active elements showed much better HDO efficiency compared to other two types of CoMo catalysts, which was consistent with peer's research work that Ni based catalyst worked well for both $1^{\text {st }}$-stage and $2^{\text {nd }}$-stage HDO of bio-oil. Although the yield of OLP is little 
lower than the reported results of $30 \mathrm{wt} \%$, the TAN, HHV, elemental contents are very close to the reported ones (Tanneru and Steele 2014; Luo 2016). Therefore, Ni based catalyst is very active for upgrading bio-oil to more stable products for further storage, transportation as well as refinery.

Table 3. Physical Properties of OLPs

\begin{tabular}{|c|c|c|c|c|}
\hline Properties & PTBO & HT-36 & HT-2300 & HT-951T \\
\hline Water content (vol.\%) & 30.93 & 1.37 & 7.80 & 3.28 \\
\hline TAN (mg KOH/g) & 179.50 & 3.85 & 6.47 & 1.10 \\
\hline $\mathrm{HHV} \mathrm{(MJ/Kg)}$ & misfire & 40.37 & 31.00 & 39.79 \\
\hline $\mathrm{C} \mathrm{(wt \% )}$ & 37.1 & 83.27 & 77.10 & 80.65 \\
\hline $\mathrm{H}(\mathrm{wt} \%)$ & 7.20 & 10.48 & 9.35 & 10.00 \\
\hline $\mathrm{O}(\mathrm{wt} \%)$ & 55.6 & 6.17 & 12.92 & 8.79 \\
\hline $\mathrm{N}(\mathrm{wt} \%)$ & 0.10 & 0.08 & 0.63 & 0.56 \\
\hline $\begin{array}{c}\text { OLPs yield based on PTBO } \\
\text { (wt\%) }\end{array}$ & - & 25.30 & 27.83 & 13.05 \\
\hline
\end{tabular}

Table 4. Exit Gas Composition of HDO Reaction

\begin{tabular}{|l|l|l|l|l|l|}
\hline Catalysts & $\mathrm{H}_{2}(\%)$ & $\mathrm{CH}_{4}(\%)$ & $\mathrm{CO}(\%)$ & $\mathrm{CO}_{2}(\%)$ & $\mathrm{C}_{2} \mathrm{H}_{6}(\%)$ \\
\hline $\mathrm{HT}-36$ & 58.84 & 1.11 & 0.92 & 7.73 & 0.04 \\
\hline $\mathrm{HT}-2300$ & 55.20 & 1.56 & 1.20 & 9.94 & 0.10 \\
\hline $\mathrm{HT}-951 \mathrm{~T}$ & 56.85 & 1.32 & 0.95 & 9.48 & 0.02 \\
\hline
\end{tabular}

\section{GC Analysis of the Exit Gas}

In previous research, deoxygenation was performed with hydrogen and ranged from 1450 to 2900 psi (Wildschut et al. 2009; Venderbosch et al. 2010; Elliott 2012). To reduce more TAN and oxygen content, 1000 psi hydrogen was utilized for hydrotreating of PTBO at $400{ }^{\circ} \mathrm{C}$ in this study. Table 4 gives the $\mathrm{GC}$ analysis of the exit gas compositions from hydrotreating of PTBO. The exit gas sample was mainly comprised of variable concentrations of $\mathrm{H}_{2}, \mathrm{CO}$, and $\mathrm{CO}_{2}$, and a minor amount of $\mathrm{CH}_{4}$. Approximately 40 to $45 \%$ of the initial hydrogen was consumed to hydrotreat the PTBO oxygenates, making it reasonable to infer that hydrotreating reaction occurred during upgrading process. This research results were consistent with the reported results that hydrotreating need around $50 \%$ hydrogen of the initial input pure hydrogen gas or syngas (Luo 2017).

\section{GC-MS Characterization of OLPs}

The GC-MS analysis of OLPs produced by HDO is shown in Fig. 1, and the chemical components are listed in Table 5. The chemical types and their relative peak area percentages changed greatly after the hydrotreatment of PTBO; also, the concentration of the main chemical components varied with the catalyst types. For HT-36, HT-2300, and HT-951T catalyst, OLPs produced $34.8 \%, 19.1 \%$, and $27.1 \%$ hydrocarbon (olefins, alkanes, aromatic), respectively. Other components are comprised of small ratios of oxygenates (such as ketones, alcohols, aldehydes) and large amount of phenols $(40.5 \%$, $47.5 \%, 56.0 \%$ ). The GC-MS analysis confirmed that HT-36 showed better catalytic performance than the other two catalysts. All three OLPs products were largely phenols, which need further hydrotreating process to convert them to hydrocarbons. The chemical components and their relative concentrations of OLP products were similar to the same bio-oil upgrading although different Ni based catalyst applied (Tanneru and Steele 2014; 
Luo 2016; Luo 2017). This further showed that HT-36 catalyst was effective for bio-oil upgrading.

Table 5. GC-MS Analysis of the OLPS

\begin{tabular}{|c|c|c|c|}
\hline Catalysts & HT-36 & HT-2300 & HT-951T \\
\hline Ketones (\%) & 1.28 & 0 & 0 \\
\hline Alcohols (\%) & 3.27 & 4.39 & 1.20 \\
\hline Aldehydes (\%) & 1.56 & 0 & 0 \\
\hline Olefins (\%) & 10.69 & 5.12 & 13.65 \\
\hline Alkanes (\%) & 15.95 & 3.62 & 7.33 \\
\hline Benzenes (\%) & 1.22 & 3.00 & 1.06 \\
\hline Polyaromatics (\%) & 6.92 & 7.39 & 5.06 \\
\hline Phenols (\%) & 40.49 & 47.52 & 55.98 \\
\hline Others (\%) & 18.50 & 25.69 & 15.75 \\
\hline
\end{tabular}

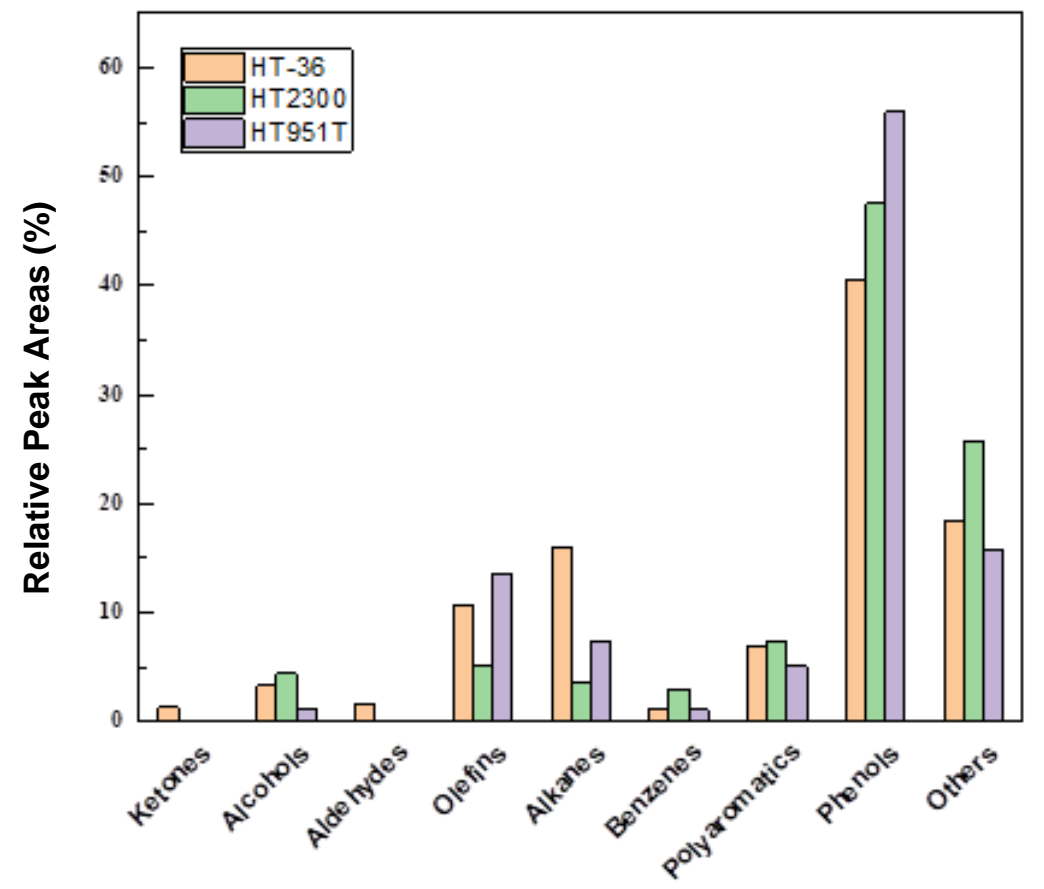

Fig. 1. GC-MS analysis of the OLPS

\section{CONCLUSIONS}

1. Pretreated bio-oil (PTBO) was catalytically upgraded to organics using a single stage hydrodeoxygenation (HDO) method. The organic phase products (OLPs) yields from HDO using HT-36, HT-2300, and HT-951T catalysts were 25.3, 27.8, and $13.0 \mathrm{wt} \%$, respectively, which contained $34.8,19.1$, and $27.1 \%$ hydrocarbons, respectively.

2. The best upgraded organic products had a respective HHV, water content value, and TAN number of $40.4 \mathrm{MJ} / \mathrm{Kg}, 1.37 \mathrm{vol} . \%$, and $3.85 \mathrm{mg} \mathrm{KOH} / \mathrm{g}$ as well as a C content of $83.3 \mathrm{wt} \%$, H content of $10.5 \mathrm{wt} \%$, and $\mathrm{O}$ content of $6.17 \mathrm{wt} \%$. 
3. The successful of one single stage upgrading bio-oil is beneficial for bio-oil storage and transportation as well as for further hydrocracking for pure hydrocarbon production.

4. Ni-based HT-36 catalyst was effective for bio-oil upgrading to more stable products.

\section{ACKNOWLEDGEMENTS}

This research was based upon work funded through the General Program of Civil Aviation Flight University of China (Grant No.: J2020-117) and National Training Programs of Innovation and Entrepreneurship for Undergraduates (Grant No.: S202010624020).

\section{REFERENCES CITED}

Anis, S., and Zainal, Z. A. (2011). "Tar reduction in biomass producer gas via mechanical, catalytic and thermal methods: A review, "Renewable and Sustainable Energy Reviews 15(5), 2355-2377. DOI: 10.1016/j.rser.2011.02.018

Ardiyanti, A. R., Khromova, S. A., Venderboschc, R. H., Yakovlevb, V. A., and Heeresa, H. J. (2012). "Catalytic hydrotreatment of fast-pyrolysis oil using non-sulfided bimetallic $\mathrm{Ni}-\mathrm{Cu}$ catalysts on a $\delta-\mathrm{Al}_{2} \mathrm{O}_{3}$ support," Applied Catalysis B: Environmental 117-118, 105-117. DOI: 10.1016/j.apcatb.2011.12.032

ASTM D5291-01 (2016). "Standard test methods for instrumental determination of carbon, hydrogen, and nitrogen in petroleum products and lubricants," ASTM International, West Conshohocken, USA.

ASTM D240-1919 (2016). "Standard test method for heat of combustion of liquid hydrocarbon fuels by bomb calorimeter," ASTM International, West Conshohocken, USA.

ASTM D664 - 07 (2016). "Standard test method for acid number of petroleum products by potentiometric titration," ASTM International, West Conshohocken, USA.

ASTM D3291-2011(2016)e1. "Standard practice for compatibility of plasticizers in poly(vinyl chloride) plastics under compression," ASTM International, West Conshohocken, USA.

Baker, E. G., and Elliott, D. C. (1993). "Method of upgrading oils containing hydroxyaromatic hydrocarbon compounds to highly aromatic gasoline," U. S. Patent No. 5180868 A.

Bridgwater, A. V., Meier, D., and Radlein, D. (1999). “An overview of fast pyrolysis of biomass," Organic Geochemistry 30(12), 1479-1493. DOI:

10.1002/9780470694954.ch80

Chen, J. M., Lu, Z. H., Yao, Q. L., Gang, F., and Luo, Y. (2018). “Complete dehydrogenation of $\mathrm{N}_{2} \mathrm{H}_{4} \mathrm{BH}_{3}$ with $\mathrm{NiM}-\mathrm{Cr}_{2} \mathrm{O}_{3}(\mathrm{M}=\mathrm{Pt}$, Rh, Ir) hybrid nanoparticles," Journal of Materials Chemistry A 6, 20746-20752. DOI: 10.1039/C8TA08050J

Cortright, R., Davda, R., and Dumesic, J. A. (2002). "Hydrogen from catalytic reforming of biomass-derived hydrocarbons in liquid water," Nature 418, 964-967. DOI: 10.1142/9789814317665_0043

Cui, H. Y., Wang, J. H., Wei, S. Q., Zhuo, S. P, Li, Z. H., Wang, L. H., and Yi, W. M. 
(2010). "Upgrading bio-oil by esterification under supercritical $\mathrm{CO}_{2}$ conditions," Journal of Fuel Chemistry and Technology 38(6), 673-678. DOI: 10.1016/S18725813(11)60003-0

Elliott, D. C., and Baker, E. G. (1989). "Process for upgrading biomass pyrolyzates," Patents. DOI: DOI: US4795841 A

Elliott, D. C. (2007). "Historical developments in hydroprocessing bio-oils," Energy \& Fuels 21(3), 1792-1815. DOI: 10.1021/ef070044u

Elliott, D. C., Hart, T. R., Neuenschwander, G. G., Rotness, L. J., and Olarte, M. V. (2012). "Catalytic hydroprocessing of fast pyrolysis bio-oil from pine sawdust," Energy \& Fuels 26(6), 3891-3896. DOI: 10.1021/ef3004587

Fang, J., Meng, Z., Li, J., Du, Y., Qin, Y., Jiang, Y., Bai, W., and Chase, G. G. (2018). "The effect of operating parameters on regeneration characteristics and particulate emission characteristics of diesel particulate filters," Applied Thermal Engineering 148, 860-867. DOI: 10.1016/j.applthermaleng.2018.11.066

Fang, J., Shi, R., Meng, Z. W., Jiang, Y., Qin, Z. H., D, Y. H, Zhang, Q., Qin, Y., Tan, J., Bai, W. L. (2019). "The interaction effect of catalyst and ash on diesel soot oxidation by thermogravimetric analysis," Fuel 258, 116151. DOI: 10.1016/j.fuel.2019.116151

Fang, J., Zhang, Q., Meng, Z. W., Luo, Y., Ou, J., D, Y. H, and Zhang, Z. L. (2020). "Effects of ash composition and ash stack heights on soot deposition and oxidation processes in catalytic diesel particulate filter," Journal of the Energy Institute 93(5), 1942-1950. DOI: 10.1016/j.joei.2020.04.009

Hu, J. L., Wildfire, C., Stiegman, A. E., Dagle, R. A., and Wang, Y. X. (2020). "Microwave-driven heterogeneous catalysis for activation of dinitrogen to ammonia under atmospheric pressure," Chemical Engineering Journal 397, 125388. DOI: 10.1016/j.cej.2020.125388

Joshi, N., and Lawal, A. (2012). "Hydrodeoxygenation of pyrolysis oil in a microreactor," Chemical Engineering Science 74, 1-8. DOI: 10.1016/j.ces.2012.01.052

Lee, C. L., and Ollis, D. F. (1984). "Catalytic hydrodeoxygenation of benzofuran and oethylphenol," Journal of Catalysis 87(2), 325-331. DOI: 10.1016/00219517(84)90193-3

Luo, Y., Guda, V. K., Steele, P. H., Mitchell, B., and Yu, F. (2016a). "Hydrodeoxygenation of oxidized distilled bio-oil for the production of gasoline fuel type," Energy Conversion and Management 112, 319-327. DOI:

10.1016/j.enconman.2015.12.047

Luo, Y., Hassan, E. B. M., Guda, V., Wijayapala, R., and Steele, P. H. (2016b). "Upgrading of syngas hydrotreated fractionated oxidized bio-oil to transportation grade hydrocarbons," Energy Conversion and Management 115, 159-166. DOI: 10.1016/j.enconman.2016.02.051

Luo, Y., Street, J. T., Steele, P. H., Entsminger, E. D., and Guda, V. K. (2016c). "Activated carbon derived from pyrolyzed pinewood char using elevated temperature, $\mathrm{KOH}, \mathrm{H}_{3} \mathrm{PO}_{4}$, and $\mathrm{H}_{2} \mathrm{O}_{2}$," BioResources 11(4), 10433-10447. DOI: 10.15376/biores.11.4.10433-10447

Luo, Y., Guda, V., Hassan, E. B. M., Steele, P. H., and Wan, H. (2016d). "Hydrodeoxygenation of oxidized and hydrotreated bio-oils to hydrocarbons in fixedbed continuous reactor," BioResources 11(2), 4415-4431. DOI: 10.15376/biores.11.2.4415-4431

Luo, Y., Hassan, E. B., Miao, P., Xu, Q., Steele, P. H. (2017). 'Effects of single-stage 
syngas hydrotreating on the physical and chemical properties of oxidized fractionated bio-oil," Fuel, 634-642. DOI: 10.1016/j.fuel.2017.07.114.

Marker, T. L., and Petri, J. A. (2009). "Gasoline and diesel production from pyrolytic lignin produced from pyrolysis of cellulosic waste," U. S. Patent No. 7578927 B2.

Mccall, M., and Brandvold, T. A. (2009). "Fuel and fuel blending components from biomass derived pyrolysis oil," U. S. Patent No. 20090253948.

Mortensen, P. M., Grunwaldt, J. D., Jensen, P. A., Knudsen, K. G., and Jensen, A.D. (2011). "A review of catalytic upgrading of bio-oil to engine fuels," Applied Catalysis A 407, 1-19. DOI: 10.1016/j.apcata.2011.08.046

Shi, K., Shao, S., Huang, Q., Liang, X. W., and Li, Y. (2011). "Review of catalytic pyrolysis of biomass for bio-oil," in: 2011 International Conference on Materials for Renewable Energy \& Environment, Shanghai, China. DOI: 10.1109/ICMREE.2011.5930821

Steele, P. H., Tanneru, S. K., and Gajjela, S. K. (2013). "Composition and methods for improved fuel production," U.S. Patent No. 0291431 A1. 2013.

Tanneru, S. K., and Steele, P. H. (2014). "Pretreating bio-oil to increase yield and reduce char during hydrodeoxygenation to produce hydrocarbons," Fuel 133, 326-331. DOI: 10.1016/j.fuel.2014.05.026

Trane, R., Dahl, S., Skjoth-Rasmussen, M. S., and Jensen, A.D. (2012). "Catalytic steam reforming of bio-oil," International Journal of Hydrogen Energy 37(8), 6447-6472. DOI: 10.1016/j.ijhydene.2012.01.023

Venderbosch, R. H., Wildschut, A. R., Oasmaa, J. A., and Heeres, H. J. (2010) "Stabilization of biomass-derived pyrolysis oils," J. Chem. Technol. Biotechnol. 85(5), 674-686. DOI: 10.1002/jctb.2354

Wei, W., Lu, Z. H., Luo, Y., Zou, A., Yao, Q., and Chen, X. (2018). "Mesoporous carbon nitride supported $\mathrm{Pd}$ and $\mathrm{Pd}-\mathrm{Ni}$ nanoparticles as highly efficient catalyst for catalytic hydrolysis of $\mathrm{NH}_{3} \mathrm{BH}_{3}$," ChemCatChem 10(7), 1620-1626. DOI: 10.1002/cctc. 201701989

Wildschut, J., Mahfud, F. H., Venderbosch, R. H., and Heeres, H. J. (2009). "Hydrotreatment of fast pyrolysis oil using heterogeneous noble-metal catalysts," Ind. Eng. Chem. Res. 48(23), 10324-10334. DOI: 10.1021/ie9006003

Zhang, L. B., Luo, Y., Wijayapala, R., and Walters, K. B. (2017). “Alcohol stabilization of low water content pyrolysis oil during high temperature treatment," Energy \& Fuels 31(12), 13666-13674. DOI: 10.1021/acs.energyfuels.7b02276

Zhang, S. L., Yao, Q. L., Li, Q.Y., Gang, F., and Lu, Z. H. (2019). "Complete hydrogen production from hydrazine borane over Raney Ni catalyst at room temperature," Energy Technology 7(3), 1800533. DOI: 10.1002/ente.201800533

Zou, H. T., Zhang, S. L., Hong, X. L., Yao, Q. L., Luo, Y., and Lu, Z. H. (2020). "Immobilization of NiePt nanoparticles on MIL-101/rGO composite for hydrogen evolution from hydrous hydrazine and hydrazine borane," Journal of Alloys and Compounds 835, 155426. DOI: 10.1016/j.jallcom.2020.155426 0925-8388

Article submitted: November 7, 2020; Peer review completed: February 13, 2021; Revised version received and accepted: February 19, 2021; Published: February 24, 2021. DOI: 10.15376/biores.16.2.2747-2755 